\title{
Temperature control of Shell and Tube Heat Exchanger by using Intelligent Controllers
}

\author{
P.Sivakumar \\ Chemical Engineering \\ Department, M.Tech Scholar, \\ Coimbatore Institute of technology \\ Anna university, chennai.
}

\author{
D.Prabhakaran, PhD. \\ Chemical Engineering \\ Department, Associate Professor \\ Coimbatore Institute of technology \\ Anna university, chennai.
}

\author{
T.Kannadasan, PhD. \\ Chemical Engineering \\ Department, Professor and Head \\ Coimbatore Institute of technology \\ Anna university, chennai.
}

\begin{abstract}
Temperature control of the shell and tube heat exchanger is characteristics of nonlinear, time varying and time lag. Since the temperature control with conventional PID controller cannot meet a wide range of precision temperature control requirement, the temperature control system of the shell and tube heat exchanger by combining fuzzy and PID control methods was designed in this paper. The simulation and experiments are carried out; making a comparison with conventional PID control showing that fuzzy PID strategy can efficiently improve the performance of the shell and tube heat exchanger.
\end{abstract}

\section{General Terms \\ Fuzzy PID Control}

\section{KEYWORDS}

Control algorithm, Fuzzy logic, PID Controller, Tuning

\section{INTRODUCTION}

In many industrial process and operations Heat exchanger is one of the simplest and important unit [1] for the transfer of thermal energy. There are different types of heat exchangers used in industries; the shell and tube heat exchanger system being most common. The main purpose of exchanger is to maintain specific temperature conditions, which is achieved by controlling the exit temperature of one of the fluids (mainly hot fluid) in response to variations of the operating conditions.

The temperature control of heat exchanger is nonlinear, time varying and time delay system. For these situations,

nonlinear control strategies can provide significant improvements over PID control [2], [12]. Control of temperature using PID controllers, compared to other methods, is more effective and economical.

The heat exchangers need to respond to highly non linear features and work well under different operating points. In order to achieve a wide range of high accurate temperature, neuro-fuzzy control and PID control methods were combined. The main design is to assume neuro-fuzzy reasoning control methods according to different error ' $\mathrm{e}$ ' and error change 'ec' to get self -tuning PID parameter based on conventional PID controller. The simulation of the controller was accomplished carrying out experiments in an actual heat exchanger system.

\section{TEMPERATURE CONTROL SYSTEM}

\subsection{Principal of temperature control in shell} and tube heat exchanger

The control of temperature in a shell-and-tube heat exchanger is demonstrated in figure 1 , with cold water flowing on the tube side and steam on the shell side [5] where steam condenses and heats the water in the tubes. The controlled variable is the tube-side outlet temperature, and the manipulated variable is the steam flow rate on the shell-side.

$$
M_{c} C_{p}\left(T_{\text {in }}-T_{\text {out }}\right)=M_{s} A
$$

where, $M_{c}, M_{s}, C_{p}, T_{\text {in }}$ and $T_{\text {out }}$ refer to cold water flow rate, steam flow rate, specific heat of water, inlet water temperature, and outlet water temperature respectively.

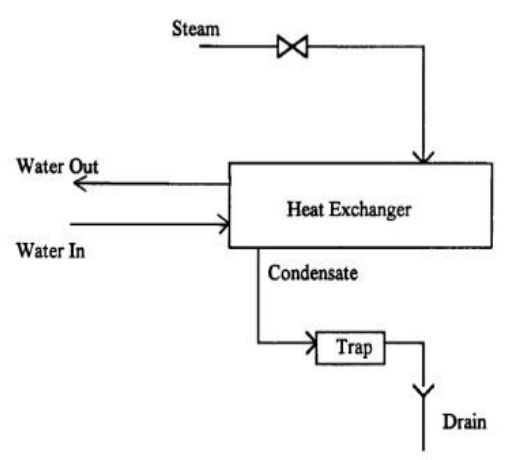

Fig 1: Shell and Tube heat exchanger

The dynamics of the process are complex because of various nonlinearities introduced into the system. The installed valve characteristic of the steam may not be linear [3]. Dead-time depends on the steam and water flow rates, the location and the method of installation of the temperature-measuring devices. To take into account the non-linearity and the deadtime, gain scheduling features and dead-time compensators have to be added. Also, the process is subjected to various external disturbances such as pressure fluctuations in the steam header, disturbances in the water line, and changes in the inlet steam enthalpy and so on. 


\subsection{Mathematical Model of heat exchanger}

The total heat in the heat exchanger system can be expressed as equation 2. [5].

$$
Q_{f}=Q_{s}+\sum_{i=1}^{n} C_{i} \rho_{i} V_{i} d T_{i}
$$

where, $Q_{f}, Q_{s}, C, \rho, V$ and $d T$ refer to total system heat productivity, total system heat dissipating capacity, specific heat capacity, heat transfer medium density, volume, and temperature variation.

Total system heat dissipating capacity $Q_{s}$ is given by equation 3 .

$$
Q_{s}=\sum_{i=1}^{n} k_{i} A_{i}\left(T_{\text {in }}-T_{\text {out }}\right)
$$

where, $k_{i}$ and $A_{i}$ refer to heat transfer coefficient, heat transfer area of the heat exchanger system.

The heat exchanger equations can be expressed as in equation 4. [12]

$$
C_{w} \rho_{w} q_{w}\left(T_{w o}-T_{w i}\right) d \tau=C_{f} \rho_{f} q_{f}\left(T_{f o}-T_{f i}\right) d \tau
$$

where, the subscripts $\mathcal{W}$ and $f$ refer to cold and hot water of the heat exchanger system. Therefore considering all above equations, the differential equation of the shell and tube heat exchanger is shown in equation 5 .

$$
\frac{d T}{d \tau}+F T=N(x-\tau)
$$

where,

$$
F=\frac{k_{i} A_{i}}{C_{o} \rho_{o} V}
$$

The transfer function of controlled object can be derived from equation 5 , it is described as the first-order with pure time delay, expressed as equation 7.

$$
G(s)=\frac{K}{1+T s} e^{-\tau s}
$$

where, $T, K$ and $\tau$ refer to time constant, system gain, and delay time.

\section{INTELLIGENT CONTROLLERS 3.1 PID Control of Shell and Tube Heat Exchanger}

PID controller is the most popular controller used because it is easy to operate and very robust. Implementation of the latest PID controller is based on a digital design. These digital PID include many algorithms to improve their performance, such as anti wind-up, auto-tuning, adaptive, fuzzy fine-tuning and Neural Networks with the basic operations remaining the same. The performance specifications such as rise time, overshoot, settling time and error; steady state can be improved by tuning value of parameters $K_{p}, K_{i}$ and $K_{d}$ of the PID controller. output

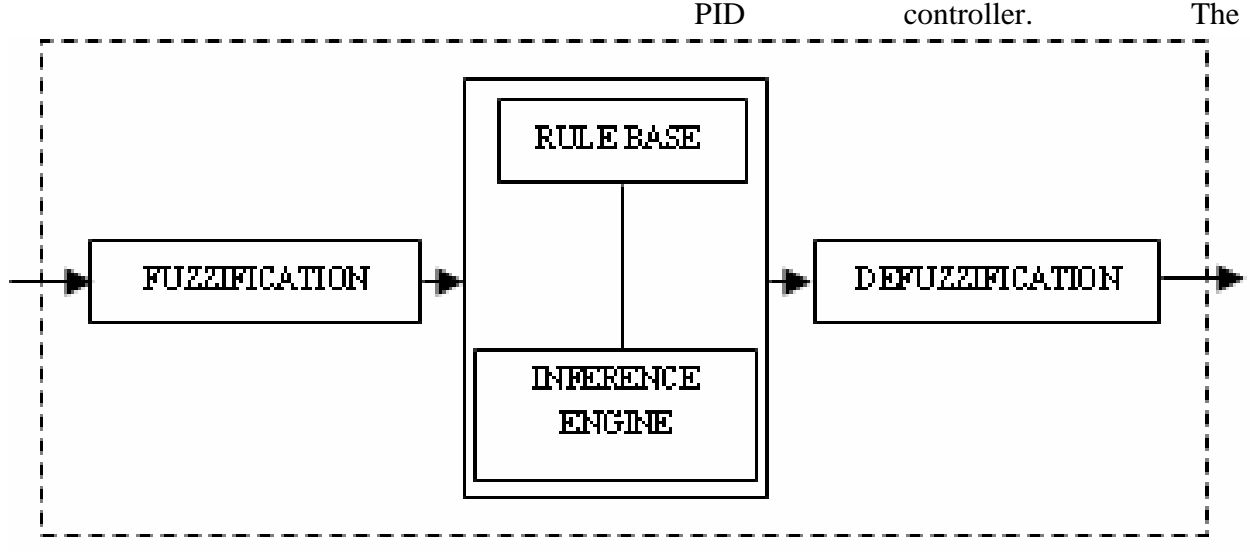

Fig 2: Main Parts of Fuzzy PID Control

is mathematically represented as equation 8 and 9 .

$$
\begin{aligned}
& y(t)=K_{P}\left[e(t)+T_{d} \frac{d e(t)}{d t}+\frac{1}{T} \int_{0}^{t} e(t) d t\right] \\
& \left.y(t)=K_{P} e(t)+K_{P} T_{d} \frac{d e(t)}{d t}+\frac{K_{P}}{T} \int_{0}^{t} e(t) d t\right]
\end{aligned}
$$

(9)

\subsection{Structure and Parts of Self tuning Fuzzy Controller}

Fuzzy logic controller as shown in Figure 2 consists of main four parts fuzzification, rule base, inference engine and defuzzification [6], [8].
Fuzzy PID Self-tuning Control takes error "e" and Change-inerror "ec" as the input of Fuzzy PID controller. Using fuzzy control rules on-line, PID parameters " $\mathrm{K}_{\mathrm{p}}$ ", " $K_{i}$ ", " $K_{d}$ " are amended, which constitute a self-tuning fuzzy PID controller, the principle of which is shown in Figure 3. The language variable values of error "e" and the error rate of change "ec" is (NB, NM, NS, ZO, PS, PM, PB) seven fuzzy values. And then setting up the suitable fuzzy control table for $\mathrm{Kp}, \mathrm{Ki}, \mathrm{K}_{\mathrm{d}}$ three parameters tuning separately[8], [9].According to the fuzzy rules table, appropriate vague and ambiguous methods is to be selected to make dynamic tuning for $K_{p}, K_{i}, K_{d}$. 


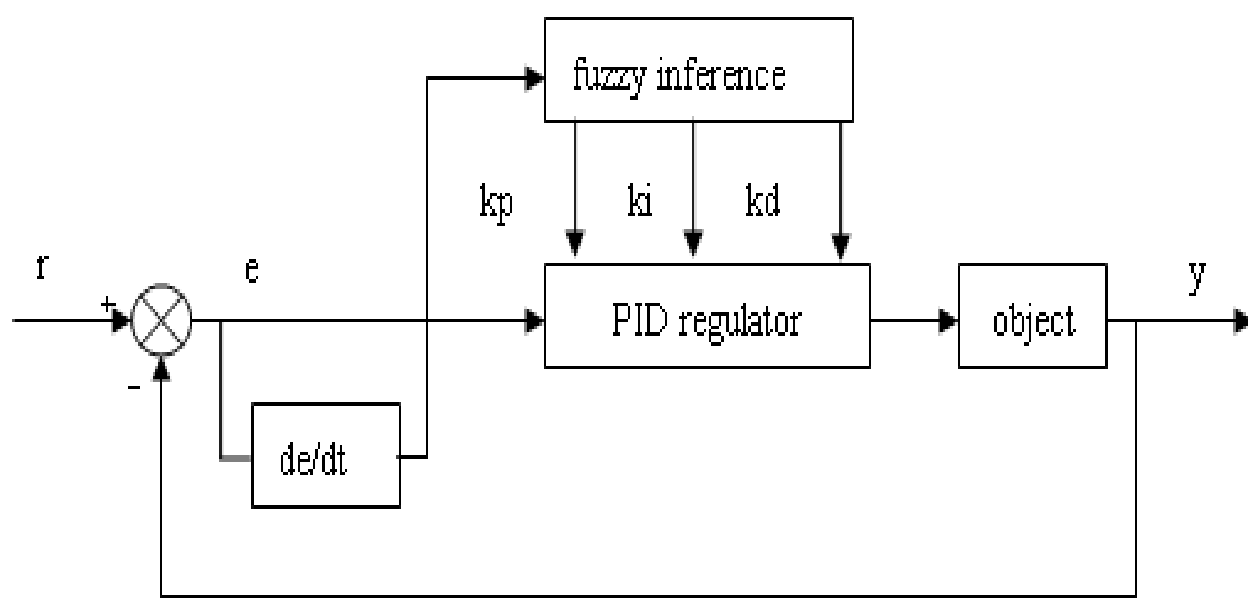

Fig 4: Input membership function

The fuzzy controller takes two inputs (e, and error change ec) and three outputs $\left(K_{p}, K_{i}, K_{d}\right)$. When the error is large, it is controlled according to the characteristics of PID control where the output value automatically closes to the given value. When the error becomes smaller to a certain extent, the fuzzy control takes effect. The input error, error change and output membership functions use triangular functions, which are shown in figure 4 and 5.
Larger $K_{p}$ is chosen to speed up the system response speed. At the same time, in order to avoid the probable differential super-saturation, smaller $K_{i}$ is chosen. In order to avoid large overshoot, the integral is limited by setting $K_{d}$ is zero.

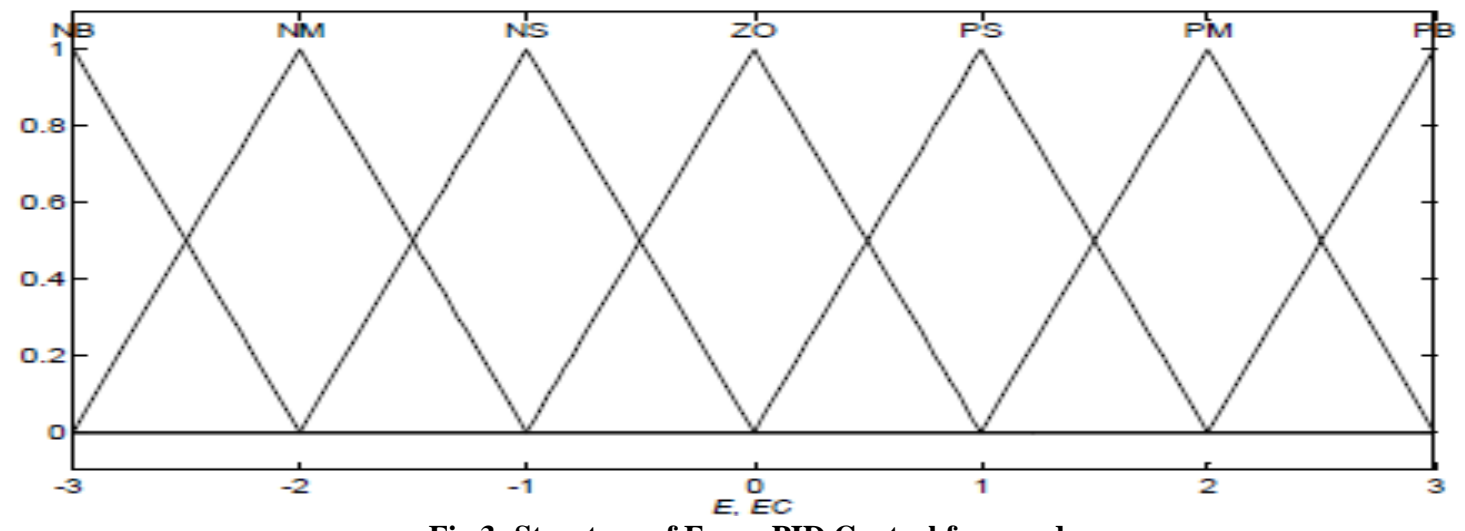

Fig 3: Structure of Fuzzy PID Control for e and ec

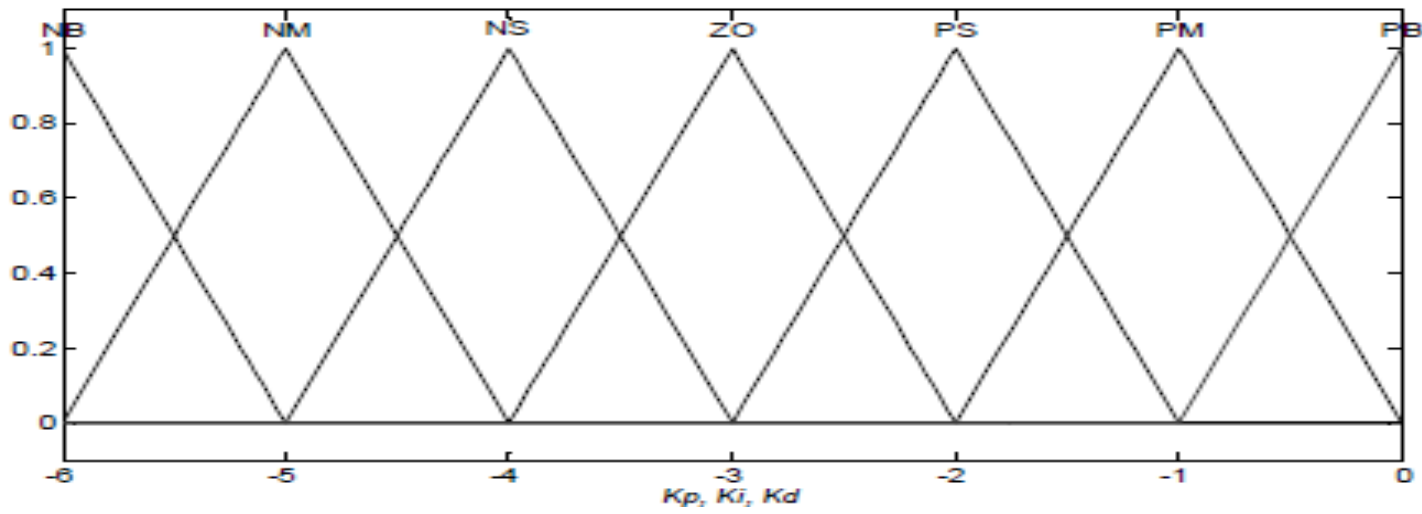

Fig 5: Output membership function for $K_{p}, K_{i}, K_{d}$ 
TABLE 1

THE FUZZY CONTROL RULE FOR $K_{p}$

\begin{tabular}{|c|c|c|c|c|c|c|c|}
\hline & NB & $\mathrm{NM}$ & NS & $\mathrm{ZO}$ & PS & PM & $\mathrm{PB}$ \\
\hline NB & $\mathrm{PB}$ & PB & PM & PM & PS & $\mathrm{ZO}$ & $\mathrm{ZO}$ \\
\hline $\mathrm{NM}$ & $\mathrm{PB}$ & PB & PM & PS & PS & $\mathrm{ZO}$ & NS \\
\hline NS & PM & $\mathrm{PM}$ & PM & PS & $\mathrm{ZO}$ & NS & NS \\
\hline $\mathrm{ZO}$ & PM & PM & PS & $\mathrm{ZO}$ & NS & $\mathrm{NM}$ & $\mathrm{NM}$ \\
\hline PS & PS & PS & $\mathrm{ZO}$ & NS & NS & $\mathrm{NM}$ & $\mathrm{NM}$ \\
\hline PM & PS & $\mathrm{ZO}$ & NS & $\mathrm{NM}$ & $\mathrm{NM}$ & $\mathrm{NM}$ & NB \\
\hline $\mathrm{PB}$ & $\mathrm{ZO}$ & $\mathrm{ZO}$ & $\mathrm{NM}$ & $\mathrm{NM}$ & $\mathrm{NM}$ & NB & NB \\
\hline
\end{tabular}

TABLE 2

THE FUZZY CONTROL RULE FOR $K_{i}$

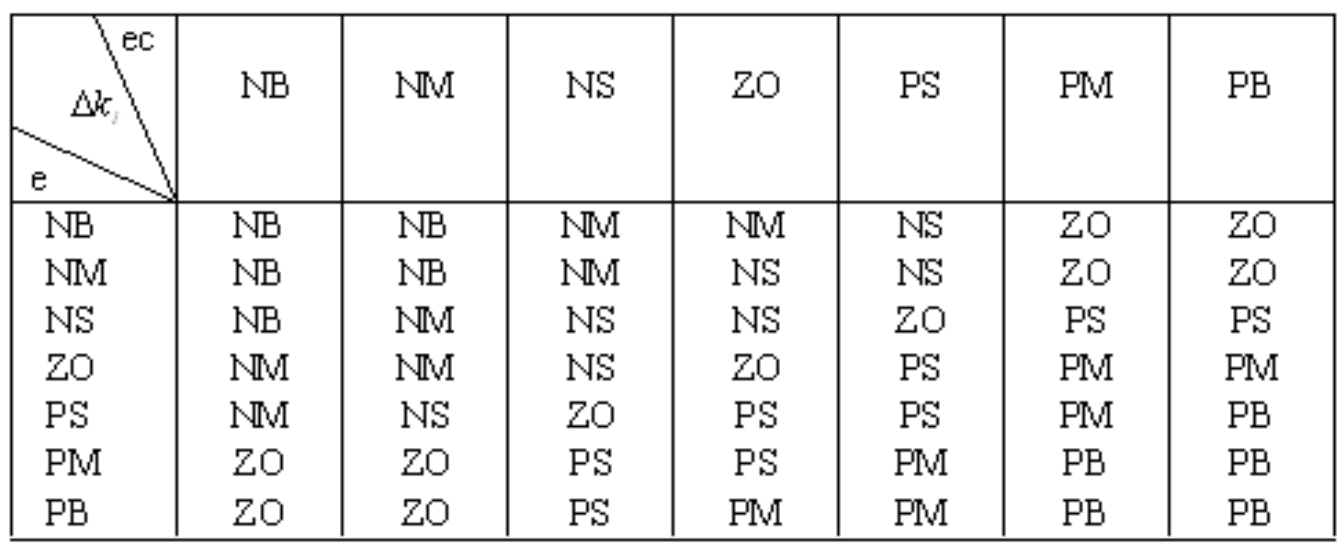

THE FUZZY CONTROL RULE FOR $K_{d}$

\begin{tabular}{|c|c|c|c|c|c|c|c|}
\hline$\Delta$ & $\mathrm{NB}$ & $\mathrm{NM}$ & NS & $\mathrm{ZO}$ & PS & PM & PB \\
\hline NB & PS & NS & NB & NB & NB & $\mathrm{NM}$ & PS \\
\hline $\mathrm{NM}$ & PS & NS & $\mathrm{NB}$ & $\mathrm{NM}$ & $\mathrm{NM}$ & NS & $\mathrm{zO}$ \\
\hline NS & $\mathrm{ZO}$ & NS & $\mathrm{NM}$ & $\mathrm{NM}$ & NS & NS & $\mathrm{ZO}$ \\
\hline $\mathrm{ZO}$ & $\mathrm{ZO}$ & NS & NS & NS & NS & NS & $\mathrm{zO}$ \\
\hline PS & $\mathrm{ZO}$ & $\mathrm{ZO}$ & 20 & $\mathrm{ZO}$ & $\mathrm{ZO}$ & $\mathrm{zO}$ & $\mathrm{zO}$ \\
\hline PM & $\mathrm{PB}$ & NS & PS & PS & PS & PS & PB \\
\hline $\mathrm{PB}$ & $\mathrm{PB}$ & PM & PM & PM & PS & PS & $\mathrm{PB}$ \\
\hline
\end{tabular}

In order to make the overshoot of the system respond relatively small and to ensure the system response speed, $K_{p}$ is set smaller, and $K_{i}$ and $K_{d}$ values are chosen respectively.

In order to make the system have better steady state, $K_{p}$ and $K_{i}$ are set larger, and to avoid oscillations near the set point, $K_{d}$ is set properly. When ec is small, $K_{d}$ is set middle, and when ec is large, $K_{d}$ is set small. According to the given rules, the control rule table of PID parameters can be obtained and the control rules for $K_{p}, K_{d}$ and $K_{i}$ is listed in table I, II and III.

\section{Defuzzification}

In this paper, the weighted average method to the fuzzy evaluation is used to get the precise control value with formula as shown in equation 10 .

$$
u_{0}=\frac{\sum_{i=1}^{n} \mu\left(u_{i}\right) \cdot u_{i}}{\sum_{i=1}^{n} \mu\left(u_{i}\right)}
$$


Where $u_{i}$ is the fuzzy set values, $\mu\left(u_{i}\right)$ is membership degree of fuzzy values and $u_{0}$ is evaluation result. After the three parameters are adjusted by the fuzzy controller, the output control parameters are calculated from the equation 9 .

\subsection{Neuro- Fuzzy Controller}

In the field of artificial intelligence, neuro-fuzzy refers to combinations of artificial neural networks and fuzzy logic. Neuro-fuzzy hybridization results in a hybrid intelligent system by combining the human-like reasoning style of fuzzy systems with the learning and connection structure of neural networks. The drawbacks are the complexity and the darkness of their structures. Industries use the PID technique since it is a crisp control. The self tuning of the P, I, D parameters are quite difficult and the resultant control is with overshoot and with large time constants. To avoid this a combination of
Neuro-Fuzzy PID controllers are used for controlling the temperature in the process.

\section{EXPERIMENTAL RESULTS AND DISCUSSIONS}

\subsection{Step Response for the Intelligent Controllers}

Comparison between conventional PID, fuzzy PID and Neuro-Fuzzy PID controller's temperature control was performed. According to the analysis fuzzy controller is designed in MATLAB and the fuzzy self-tuning PID control system model is designed by SIMULINK. The step response of the Fuzzy control and conventional control is shown in Figure

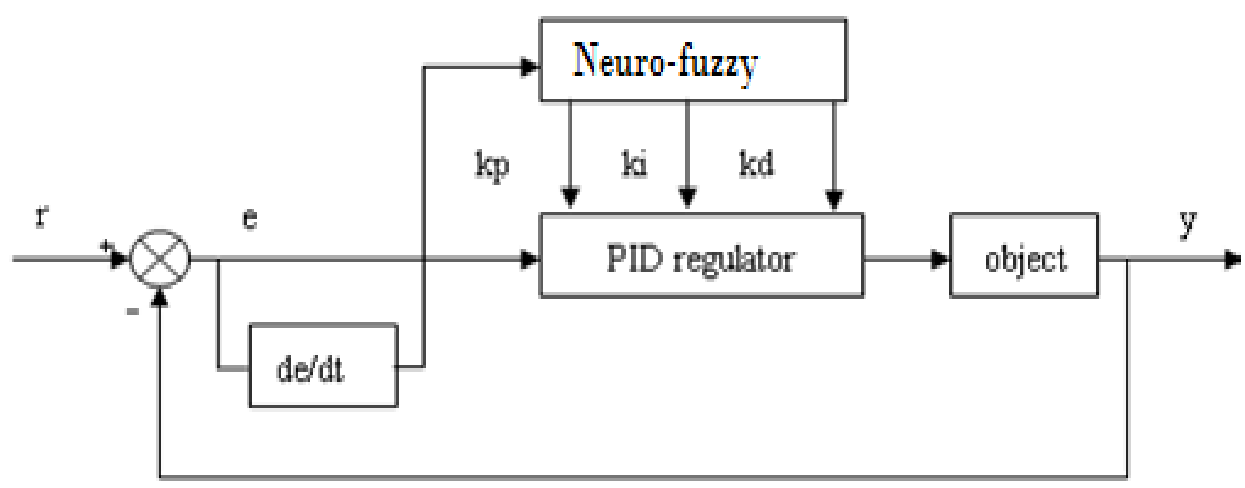

Fig 6: Structure of Neuro-Fuzzy PID Control

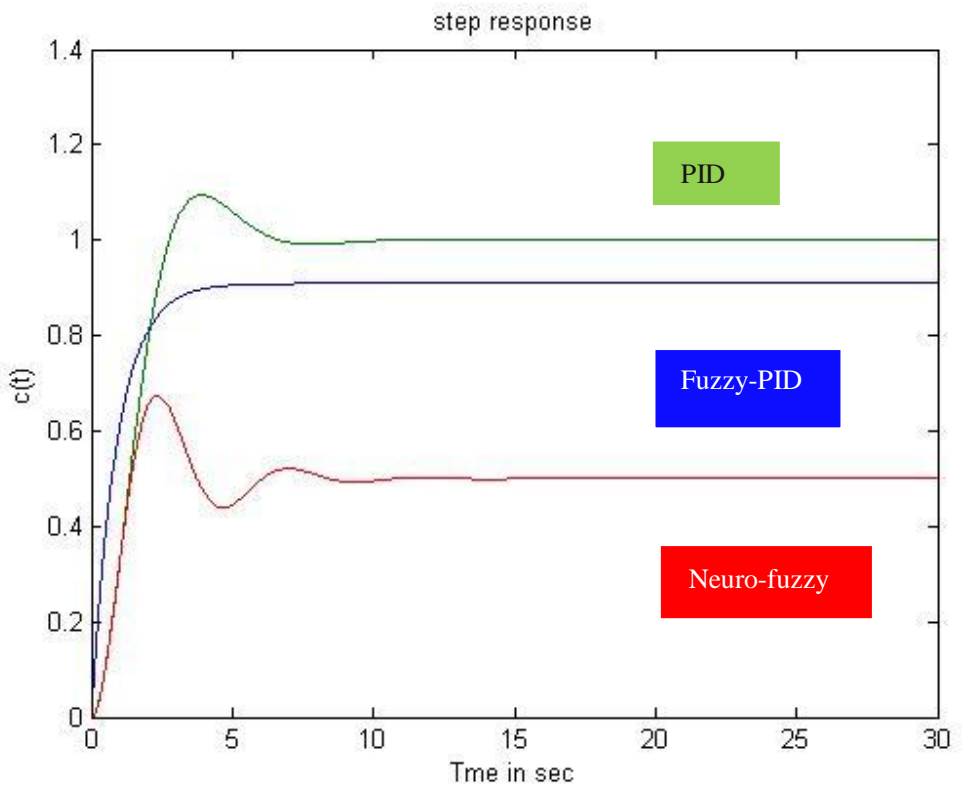

Fig 7: Step Response for the Intelligent Controllers 


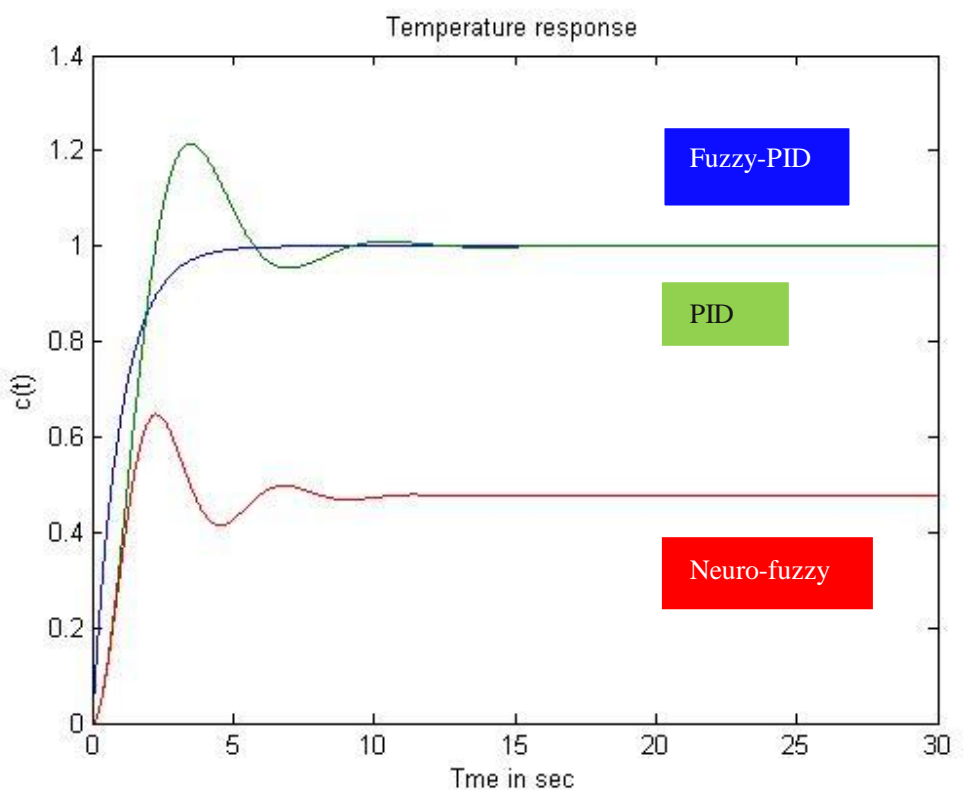

Fig 8: Response of Temperature control

The initial tuning of the PID controller is accomplished based on the Ziegler-Nicholes method, and the gain coefficients are $K_{p}=1.1, K_{i}=0.003$ and $K_{d}=52$. Fuzzy PID Controller has a small overshoot, fast response and the steady state error is less than $1 \%$.

\subsection{Response of the Temperature control system}

The temperature control experiment is conducted in the actual Shell and tube heat exchanger system. The target outlet temperature of heat exchanger is $60^{\circ} \mathrm{C}$ and figure 7 shows the response of heat exchanger.

The results suggest that neither the settling time nor control accuracy is satisfied enough when conventional PID controller is used in shell and tube heat exchanger. The steady state error of the PID controller is greater than fuzzy PID. The experimental results shows that fuzzy self-tuning PID control has better dynamic response and steady state error characteristics.

\subsection{Comparison of various parameters}

Table IV shows the comparison of various parameters from the above graph for the various types of Controllers.

TABLE 4

COMPARISON OF PARAMETERS

\begin{tabular}{|l|l|l|l|}
\hline Parameters & PID & $\begin{array}{l}\text { Fuzzy } \\
\text { PID }\end{array}$ & $\begin{array}{l}\text { Neuro Fuzzy } \\
\text { PID }\end{array}$ \\
\hline Rise Time & 1.8 & 2.6 & 3.2 \\
\hline Peak over shoot & 0.68 & 0.82 & 1.2 \\
\hline Settling Time & 14 & 5.8 & 8.6 \\
\hline Peak Time & 2.6 & 4.1 & 4.2 \\
\hline
\end{tabular}

\section{CONCLUSION}

In this paper design of a temperature control of a shell and tube heat exchanger based on Neuro-fuzzy PID control was discussed by comparing it with PID and Fuzzy PID. The analysis fuzzy controller is designed in MATLAB and the fuzzy self-tuning PID control system model is designed by SIMULINK. The results suggested that self-tuning parameter fuzzy PID controller has a smaller system overshoot, faster response and less steady state error thereby making it stronger than conventional PID controller. It was thus concluded that fuzzy self-tuning PID control has better dynamic response and steady state error characteristics. The control rule table of PID parameters was obtained and the control rules for $K_{p}, K_{d}$ and $K_{i}$ was tabulated. The actual system used obtains a good control effect and can satisfy the requirements of the temperature control system of the shell and tube heat exchanger.

\section{REFERENCES}

[1] H. Thal-Larsen, 1960, Dynamics of heat exchangers and their models, ASME J. Basic Eng., pp. 489 - 504.

[2] M.Chidambaram, and Y.S.N. Malleswara rao, 1992,Nonlinear Controllers for heat exchangers, J. Proc. Cont., vol 2(1), pp 17-21.

[3] A.W.Alsop, and T.F.Edgar, 1998, Non-linear heat exchanger control through the use of partially linearised control variables, Chein. Eng. Commn.,vol.75, pp $155-$ 170 .

[4] Wang Li-Xin, 1994,Adaptive fuzzy systems and control: Design and stability analysis [M], Prentice-Hall Englewood chiffs NewJersey.

[5] H. Yamashita, R. Izumi, S. Yamaguchi, 1978, Analysis of the dynamic characteristics of cross-flow heat exchangers with both fluids unmixed, Bull. JSME, vol. 21 (153), pp 479-485. 
[6] Hassan B.Kazemian, 2001,Development of an intelligent Fuzzy Controller, IEEE International Fuzzy Systems Conference. Vol.1, , pp. 517-520.

[7] Mann G. K.I., Hu B.G.Gosine R.G, 1999, Analysis of direct fuzzy PID controller structures, IEEE Trans on Systems, Man and Cybernetics. Vo1.29, pp. 371-388.

[8] M. Sugeno, 1985, Industrial applications of fuzzy control, Amsterdam, The Netherlands: Elsevier.

[9] Li, H.X. \& H. Gatland, 1996, Conventional fuzzy logic control and its enhancement, IEEE Transactions on Systems, Man and Cybernetics, 26(10), pp.791-797.
[10] Jean-Jacques E. Slotine, Weiping Li, 1991,applied nonlinear control, Pretice-hall, Inc., London, pp. 278282.

[11] George K. I. Mann, Bao-Gang Hu, and Raymond G. Gosine, 2001,Two-level tuning of fuzzy PID controllers, IEEE transactions on systems, man, and cybernetics-part B: cybernetics, Vol. 31, No.,pp. 263-269.

[12] K. M. Hangos, J. Bokor, and G. Szederkényi, 2004, Analysis and control of nonlinear process control systems, Advanced Textbooks in Control and Signal Processing, 1st Edition, Ch. 4, Springer-Verlag London limited, pp. 55-61. 